\title{
Managing patients with chronic cough: challenges and solutions
}

\author{
Jeanne-Marie Perotin ${ }^{1,2}$ \\ Claire Launois' \\ Maxime Dewolf' \\ Antoine Dumazet ${ }^{1}$ \\ Sandra Dury' \\ François Lebargy' \\ Valérian Dormoy ${ }^{2}$ \\ Gaëtan Deslee ${ }^{1,2}$ \\ 'Department of Respiratory Diseases, \\ University Hospital of Reims, Reims, \\ France; ${ }^{2}$ INSERM UMRS I 250, \\ University Hospital of Reims, Reims, \\ France
}

Correspondence: Gaëtan Deslee Department of Respiratory Diseases, University Hospital of Reims, 45 rue Cognacq Jay, 51092 Reims Cedex, France $\mathrm{Tel}+333267876 \mid 4$

Email gdeslee@chu-reims.fr
This article was published in the following Dove Press journal:

Therapeutics and Clinical Risk Management

\begin{abstract}
Chronic cough is a common complaint and a frequent cause of medical consultation. Its management can be difficult. We present here an overview of the current guidelines for the management of chronic cough. Different steps are detailed, including the initial research of an obvious etiology and alert signs that should lead to further investigation of underlying condition. The diagnosis of the most frequent causes: asthma, non-asthmatic eosinophilic bronchitis, gastroesophageal reflux disease and upper airway cough syndrome should be considered, assessed and treated accordingly. Recent advances have been made in the comprehension of refractory chronic cough pathophysiology as well as its pharmacologic and non-pharmacologic treatment, especially speech pathology therapy.
\end{abstract}

Keywords: asthma, gastroesophageal reflux, upper airway cough syndrome, chronic hypersensitivity syndrome, refractory chronic cough, speech pathology therapy

\section{Introduction}

Chronic cough is defined as a cough lasting more than 8 weeks. ${ }^{1,2}$ It is a frequent cause of medical consultation and is associated with a large number of pulmonary and extrapulmonary disorders. Its prevalence is estimated between 11 and $13 \%$ of the population, ${ }^{3,4} 9.6 \%$ in a recent meta-analysis of 90 studies. ${ }^{5}$ In this study, the prevalence of chronic cough was higher in Oceania (18.1\%), Europe (12.7\%) and America (11\%) than in Asia (4.4\%) and Africa (2.3\%).

The management of chronic cough can be challenging for both doctors and patients. In a recent survey performed in 1,120 people with chronic cough, more than $70 \%$ of the subjects benefit from more than 3 consultations in connection with their chronic cough; a diagnosis was given in only $53 \%$ of the cases. Moreover, only $30 \%$ of the subjects felt that "their doctor had dealt with their cough thoroughly" and the medication was judged as having limited $(57 \%)$ or no effectiveness $(36 \%) .{ }^{3}$ In this study, $96 \%$ of the subjects described an alteration of their quality of life (QoL), 91\% felt depressed, 94\% reported an impact of chronic cough on their family. Different physical complications of chronic cough have been described, including syncope, ${ }^{6}$ cardiac arrhythmias, ${ }^{7}$ incontinence ${ }^{8}$ or rib fracture. ${ }^{9}$ A reliable evaluation of chronic cough impact can be difficult and requires suitable tools. A recent guideline on tools for assessing outcomes in chronic cough recommends the use of validated and reliable health-related QoL questionnaires (Leicester Cough Questionnaire, Cough-Specific Quality-of-Life Questionnaire, Parent Cough-Specific Quality of Life Questionnaire) to assess the impact of cough. The use of acoustic cough counting is currently recommended to assess cough frequency. ${ }^{10}$ 
Table I Main steps currently recommended in chronic cough management

I. Initial clinical evaluation
Checking for warning signs
Environmental and occupational assessment
Drugs intake (ACE inhibitor)
2. Most frequent causes assessment and treatment
Asthma and cough-variant asthma
Non-asthmatic eosinophilic bronchitis
Gastroesophageal reflux disease
Upper airway cough syndrome
3. Consider other causes in case of inadequate response to treatment
Non-asthmatic pulmonary diseases
Obstructive sleep apnea
Cardiac arrythmias
Somatic cough syndrome
4. Consider refractory chronic cough

Abbreviation: ACE, angiotensin-converting enzyme.

Given the high frequency of chronic cough, its important physical, psychological and social impact as well as its complex management, standardized procedures for diagnosis and treatment have been proposed. ${ }^{1,2,4,11-14}$ Multiple countries have developed guidelines for managing cough, ${ }^{1,15-20}$ of varying quality. ${ }^{21}$ These guidelines highlight the need for different steps, including research into an obvious etiology, diagnosis and treatment of the causes, including asthma, gastroesophageal reflux disease (GORD) and upper airway cough syndrome (UACS) secondary to rhinosinus diseases, and the management of the chronic refractory cough. Some guidelines have focused on selected contexts of chronic cough, including cough in palliative care, ${ }^{22}$ cough in lung cancer ${ }^{23}$ or workplace-related cough. ${ }^{24}$ The variability in success in treating chronic cough could be partly related to a lack of fidelity to the main elements of the diagnosis/therapeutic guidelines. ${ }^{25}$ In this review, we will summarize the different steps recommended or suggested by the most recent guidelines in chronic cough management (Table 1). We will then focus on current research findings, including the recent advances in refractory chronic cough mechanisms understanding and treatment.

\section{Research into an obvious etiology or aggravating factor Initial clinical evaluation}

The recommended initial evaluation should include detailed interview and clinical exam as well as systematic chest $\mathrm{X}$-ray, searching for signs of obvious underlying condition or warning symptoms that should lead to specific investigations. These warning signs include abnormal clinical respiratory and/or general exam, abnormal chest X-ray, smoking history of $>20$ pack-years, onset or modification of cough or cough associated with voice abnormalities in a smoker over 45 years, hemoptysis, dyspnea, significant sputum production, hoarseness, fever, weight loss, GORD, failure of empirical treatment for GORD, hematemesis, dysphagia or recurrent pneumonia. ${ }^{2,11,26}$

\section{Environmental exposure assessment}

The population attributable risk of work-related chronic cough is estimated to be $4 \%-18 \%$ and numerous causal agents have been described. ${ }^{24}$ The evaluation of occupational and environmental factors in the assessment of chronic cough is recommended and a diagnosis algorithm has been recently proposed by the European Academy of Allergy and Clinical Immunology (EAACI), including a first step detailed clinical and occupational history. ${ }^{24}$ However, occupational exposure appears to be rarely addressed in detail. ${ }^{27}$

Smoking is obviously a risk factor for chronic cough. A recent large study performed on 14,669 subjects in Copenhagen found a prevalence of chronic cough of $3 \%$ in never smokers, $4 \%$ in former smokers and $8 \%$ in current smokers. ${ }^{28}$ Moreover, the results of this study suggest that the main risk factors of chronic cough could differ depending on smoking status, including i) female sex, asthma and GORD in never smokers; ii) obesity, asthma and GORD in ex-smokers and iii) airflow limitation in current smokers. ${ }^{28}$ As stated above, a smoking history $>20$ pack-years or a modification of the cough in a smoker $>45$ years old should lead to further investigations. ${ }^{2,11,26}$

The role of air pollutants in chronic cough has been evaluated in different studies. Several pollutants have been shown as being risk factors for chronic cough in general population and in asthmatic patients, depending on the level of exposure. A very recent Japanese study found that exposure to polycyclic aromatic hydrocarbon, nitrogen dioxide and sulfur dioxide was associated with an increase in cough prevalence among adults with chronic cough. ${ }^{29}$ In a cross sectional survey of 200 Russian adults, exposure to heavy mining and refining industrial air pollution was also associated with chronic cough, after adjustment for smoking status, age and sex (OR 2.16, 95\% CI 1.07-4.35)..$^{30}$ Living close $(<100 \mathrm{~m})$ to a major road in Beijing, China led to a higher risk of chronic cough compared to living $>200 \mathrm{~m}$ (OR 2.54, $95 \%$ CI $1.57-4.10){ }^{31}$

Indoor pollution can also be associated with chronic cough in fragile populations. A European study performed in elderly people living in nursing homes showed an excess risk of cough with elevated PM10 (particles with a 50\% 
cutoff aerodynamic diameter of $<10 \mu \mathrm{m}$, OR $1.73,95 \%$ CI 1.17-10.3), nitrogen dioxide (OR 1.56, 95\% CI 1.03-2.41) and $\mathrm{CO}_{2}(\mathrm{OR} 2.01,95 \% \mathrm{CI} 1.55-2.63){ }^{32}$

\section{Angiotensin-converting enzyme (ACE) inhibitor medications}

Chronic cough is a frequent side effect of ACE inhibitor treatment. Its incidence is estimated between 3.9\% and $35 \%{ }^{33,34}$ A large analysis of almost 27,500 patients with vascular disease identified that female gender, age $>65$ years and concomitant use of lipid lowering agents were clinical predictors of ACE inhibitor induced dry cough (OR 1.92, 95\% CI 1.68-2.18; OR 1.53, 95\% CI 1.35-1.73 and OR 1.37, 95\% CI 1.18-1.59, respectively). ${ }^{33}$ Several genetic variants (CLASP 1, ABO, KCNIP4) have also been identified as risk factors for ACE inhibitor induced cough. ${ }^{35-37}$

ACE inhibitor related cough usually occurs in the first weeks of treatment, but later occurrences (several months of treatment) are not infrequent. ${ }^{33,34}$ After discontinuation of ACE inhibitor treatment, cough usually disappears in a few weeks ( $<3$ months). ${ }^{34}$

\section{Infection}

A viral airway infection usually induces a cough lasting no more than 3 weeks. However, a number of patients with chronic cough describe an initial "viral infection". A recent review highlighted that the function of the airway sensory nerves can be altered by the viral infection..$^{38}$ Indeed, viral infection of airways leads to a stimulation of the sensory C-fibers (afferent nerves) by inflammatory mediators and products of oxidative stress in the respiratory tract, as well as an increase in their excitability and a change in sensory nerve gene expression. Post-viral cough could be linked to an alteration of the central neural networks involved in cough, including a decrease in the cough reflex threshold. Viral infection also induces the expression of cough receptors that can be inhibited by tiotropium. However, the exact mechanisms involved in postinfection cough are not entirely elucidated. ${ }^{38,39}$ In case of a cough $>8$ weeks after an initial viral infection, an alternative diagnosis should be considered..$^{40}$

Bordetella pertussis infection can be associated with acute, persistent or chronic cough. ${ }^{41,42}$ In a very recent metaanalysis of clinical characteristics of cough associated with B. pertussis infection, ${ }^{43}$ paroxysmal cough and absence of fever have a high sensitivity ( $93.2 \%$ and $81.8 \%$, respectively) and posttussive vomiting and whooping had a high specificity (77.7\% and $79.5 \%$ ). The laboratory diagnosis of B. pertussis infection can be performed by culture (100\% specificity), PCR ( $88 \%-100 \%$ specificity) or serology $(72 \%-100 \%$ specificity). ${ }^{43}$

\section{Frequent causes of chronic cough}

In case of normal chest X-ray, no smoking history and no ACE inhibitor treatment, it is recommended to consider etiologies that will directly impact on the initial treatment., ${ }^{2,11}$ These causes can be separated into "eosinophilic airways" (asthma and cough variant asthma, non-asthmatic eosinophilic bronchitis [NAEB]) and "non-eosinophilic airways" (GORD, UACS).

\section{Asthma and cough variant asthma}

Asthma assessment is recommended in chronic cough management. ${ }^{2,11}$ Asthma and cough-variant asthma are a frequent cause of chronic cough, involved in $14 \%-41.3 \%$ of the cases, ${ }^{44,45}$ about one quarter in non-smoking adults. ${ }^{46,47}$ Although chronic cough is usually associated with other symptoms as wheezing or dyspnea, it can occur isolated. The diagnosis relies on the evidence of airway hyperresponsiveness, either by spirometry with bronchodilator reversibility testing or by methacholine inhalation challenge in case of normal physical examination and spirometry findings. ${ }^{2,47}$ An allergy evaluation should be performed (skin prick tests and/or specific IgE measurements). ${ }^{2}$ However, the diagnosis will be established only in case of cough resolution with specific antiasthmatic treatment. ${ }^{47}$ In the absence of methacholine challenge, an empirical treatment by corticosteroid should be given, but a response to this treatment would not allow the differential diagnosis of NAEB.$^{2,47}$ The therapeutic management of cough variant asthma does not differ from that of usual form of asthma.

\section{Non-asthmatic eosinophilic bronchitis}

NAEB is characterized by eosinophilic inflammation ( $\geq 3 \%$ in induced sputum) and response to corticosteroid treatment, with no variable airflow obstruction or airway hyperresponsiveness. ${ }^{48}$ It represents $10 \%-30 \%$ of chronic cough cases. ${ }^{46,48}$ Allergy assessment or empirical treatment can be of interest in the initial characterization of the patient. ${ }^{2} \mathrm{FeNO}$ measurement may not be useful to predict EB in non-asthmatic subjects with chronic cough ${ }^{49}$ There is no clear recommendation for the treatment of NAEB. Low/medium doses of inhaled corticosteroid (ICS) for 4-8 weeks are usually efficient but long-term treatment can be necessary. In patients with severe cough or refractory to ICS, oral prednisolone (10-30 mg/d) for 3-5 days might be proposed. ${ }^{48} \mathrm{Up}$ to $60 \%$ recurrence has 
been described after treatment cessation, and associated with sputum eosinophilia. ${ }^{50}$

\section{GORD}

It is recommended to investigate GORD in chronic cough management. ${ }^{2}$ GORD is described in $4.6 \%-85.4 \%$ of chronic cough. ${ }^{46,51}$ GORD is typically characterized by symptoms such as daily heartburn and regurgitation, but can frequently be asymptomatic. ${ }^{52}$ Moreover, GORD is a frequent disease and the distinction between GORD/chronic cough coexistence and GORD-related chronic cough can be challenging. Different mechanisms of GORD involvement in chronic cough have been described, including a direct effect of reflux on the bronchial tree via microaspiration, an increase of cough reflex sensitivity by distal esophageal acid infusion and a laryngeal neuropathy caused by harmful effects of GOR products on the larynx. ${ }^{11,53,54}$

The diagnosis of chronic cough related to GORD requires a careful history. Patients should be referred to a gastroenterologist in case of warning signs in order to evaluate the need for upper endoscopy. In the absence of warning signs, current guidelines recommend the use of a proton pump inhibitor (PPI) associated with diet and lifestyle changes ${ }^{2,55}$ for a limited time period. The efficacy of PPI treatment in cough needs to be assessed, as about $30 \%-50 \%$ of patients with reflux-related chronic cough do not respond to PPI treatment (especially in the case of non-acidic or gaseous reflux). If the cough does not improve, PPI treatment should be stopped. ${ }^{56}$ Physiological testing should be reserved for refractory patients with strong clinical suspicion or being considered for anti-reflux surgery. ${ }^{57}$ In refractory cases after a short trial of PPI, an ambulatory reflux monitoring by $24 \mathrm{~h}$ esophageal $\mathrm{pH}$ and impedance monitoring can be performed off PPI treatment in order to confirm GORD diagnosis and limit empirical use of GORD treatment. ${ }^{56}$ This technique can detect episodes of both liquid and aerosolized acid $(\mathrm{pH}<4)$, mildly acid ( $\mathrm{pH} 4-7)$ and alkaline $(\mathrm{pH}>7)$ reflux. ${ }^{11}$ Different biomarkers for reflux associated cough have been studied, including pepsin and lipid-laden alveolar macrophages in broncho-alveolar lavage. However, these markers did not show a good specificity or sensibility so far and are not currently recommended for routine investigations. ${ }^{58-60}$

\section{UACS secondary to rhinosinus diseases}

UACS assessment is recommended. ${ }^{2}$ Initial assessment of UACS can include sinus imaging, nasopharyngoscopy and allergy evaluation. Empirical treatment can be started including anti-histamine and/or nasal corticosteroid depending on underlying nasosinusal pathology., 2,46,61 UACS, previously referred to as post-nasal drip (PND) syndrome, is involved in $18.6 \%-67 \%$ of chronic cough cases. ${ }^{46,62,63}$ No consensual definition of UACS exists. ${ }^{61}$ In UACS patients, cough can be caused by a variety of upper respiratory disorders, including allergic and non-allergic rhinitis and chronic rhinosinusitis. ${ }^{11,46,61}$

Several mechanisms have been hypothesized. Chronic cough was initially thought to result from PND inducing mechanical or chemical stimulation of the afferent nerves innervating the pharynx, larynx or lower airways. However, the cough appeared to be uncommon in subjects with PND and may not be associated with PND. ${ }^{61}$ Another hypothesis is a lower airway inflammation resulting from PND aspiration or mechanical stimulation from the cough itself. The inflammatory mediators released would induce a stimulation of cough receptors previously activated by a nervous reflex induced by inflammatory stimulation of nasal mucosa. ${ }^{61}$ The sensory neural hypersensibility hypothesis described an increased cough sensitivity related to a nasal neural activation and a pharyngeal and/or laryngeal increased neural sensitivity. However, the mechanisms underlying this hypothesis are not fully understood. ${ }^{61}$

\section{Other causes to consider}

In case of the absence of these 4 most common causes after investigation or inadequate response to optimal treatment, other diagnoses and/or further investigations should be considered. $^{2}$

\section{Non-asthmatic pulmonary diseases}

Numerous pulmonary diseases can induce chronic cough. Among them, COPD has been described in 11\% of the patients with chronic cough, bronchiolitis in $7.8 \%$, interstitial lung disease in $2.5 \%$, lung cancer in $2 \%$, bronchiectasis in $1 \%-1.5 \%$ and mycobacterial infection in $1 \%-1.8 \% .^{51,62,64}$ Chronic cough occurs in 14\%-74\% of COPD patients, frequently associated with sputum production. The presence of chronic bronchitis is associated with a higher risk of exacerbation, faster lung decline and mortality. Chronic cough is also associated with an impairment of health-related QoL in COPD. ${ }^{65}$ In idiopathic pulmonary fibrosis (IPF), chronic dry cough is one of the predominant symptoms, associated with shortness of breath, and frequently the first occurring symptom. Chronic cough affects $70 \%-85 \%$ of patients with IPF, has a significant impact on QoL and is a marker of disease severity and progression. ${ }^{66}$ Its mechanisms and therapeutic options have been recently reviewed. ${ }^{66}$ 


\section{Obstructive sleep apnea (OSA)}

OSA has been reported by $44 \%-68 \%$ of patients with chronic cough. ${ }^{67,68}$ The prevalence of chronic cough in subjects with OSA was estimated as 33\%-39\% (12.5\% in subjects without OSA) ${ }^{69,70}$ Two mechanisms of OSA-associated cough have been suggested. First, an upper airway inflammation related to snoring and frequent airway obstruction could lead to increased cough sensitivity associated with airway inflammation, as described above. ${ }^{71}$ Second, an increased prevalence of GORD has been described in OSA-related cough and GORD has been identified as an independent predictor of cough in patients with OSA. ${ }^{70}$

Clinical features of OSA-related cough include snoring, nocturnal cough, nocturnal heartburn and symptoms of rhinitis. OSA should also be considered in case of raised BMI and clinical signs of OSA. An important feature of OSArelated cough is the absence of excessive daytime somnolence and frequently normal Epworth sleepiness scores. ${ }^{71}$ The assessment of OSA can be performed in refractory chronic cough or in case of clinical signs of OSA. Continuous positive airway pressure (CPAP) treatment has been reported as effective, with cough improvement in $93 \%{ }^{72}$ and cough resolution in $67 \%{ }^{70}$ following CPAP therapy.

\section{Cardiac arrythmias}

The involvement of cardiac arrythmias in chronic cough has been shown in a study assessing 120 patients with premature ventricular complexes (PVCs). ${ }^{7}$ In this study, $5 \%$ of the subjects (6 patients) presented PVC-related chronic cough, confirmed by multichannel recording of sleep-disordered breathing. In these patients, cough was characterized by a sudden need to cough preceded by a tickling feeling in the throat. The cough could not be stopped voluntarily and looked like a rapid expelling of air not preceded by inspiration. The frequency of cough decreased during the night. Cough was improved in 5 patients after treatment with oral antiarrhythmic drugs. When radiofrequency ablation procedure was performed (4 patients), it resulted in complete resolution of both arrhythmia and cough. ${ }^{7}$

\section{Somatic cough syndrome}

The term somatic cough syndrome (previously psychogenic cough) is used to describe a cough that has no obvious medical etiology, is refractory to medical management and is considered to have a psychiatric or psychological basis. ${ }^{73}$ The diagnosis of somatic cough syndrome requires the absence of alternative diagnosis after investigation of other diagnoses and the patient meets the Diagnostic and Statistical
Manual of Mental Disorders (DSM-5) criteria for a somatic symptom disorder. ${ }^{74}$ These DSM-5 criteria include one or more somatic symptoms that are distressing or result in significant disruption to daily life, such as disproportionate and persistent thoughts about the seriousness of the symptoms, high levels of anxiety about symptoms or excessive time and energy devoted to the symptoms. ${ }^{74}$ In patients with refractory unexplained chronic cough, American College of Chest Physicians (ACCP) recommendations indicate that the diagnosis of tic cough can be made when the patient presents the core clinical features of tics including suppressibility, distractibility, suggestibility, variability, and the presence of a premonitory sensation whether the cough is single or one of many tics. ${ }^{73}$ In patients diagnosed with somatic cough syndrome, non-pharmacologic trials of hypnosis, suggestion therapy, reassurance, counselling or a referral to a psychologist or a psychiatrist are recommended. ${ }^{74}$

\section{Chronic cough in specific populations Elderly population}

The prevalence of chronic cough has been specifically assessed in elderly populations. A study performed in Korea in people aged $>65$ years found a prevalence of $4.6 \%$ of chronic cough. Chronic cough was associated with impairment of QoL, smoking habits, asthma, allergic rhinitis, uncontrolled diabetes ( $\mathrm{HbA} 1 \mathrm{c} \geq 8 \%$ ) and constipation. ${ }^{75}$ In a European study assessing elderly people living in nursing homes with a mean age of 82 years, the prevalence of "usual cough" was $25.1 \%{ }^{32}$

\section{Athletes}

Management guidelines for cough in athletes have recently been published..$^{76}$ Cough is a frequent symptom in athletes, associated with exposure to the sport training environment, especially in winter athletes, and predominantly following intense exercise. ${ }^{76,77}$ The management of chronic cough in athletes should take into account the most frequent causes (asthma, exercise induced bronchoconstriction, respiratory tract infection, upper airway cough) and environmental exposure related to sport training environment. ${ }^{76}$

\section{Immunocompromised population}

In ambulatory immunocompromised adults, the causes of chronic cough appear to be similar to the general population. ${ }^{78}$ The management of chronic cough in immunocompromised adults should take into account the type and severity of immune defect, geographic location and social determinants. 
Tuberculosis should be specifically assessed in case of HIV infection and living in a region with a high prevalence of tuberculosis. $^{78}$

\section{Refractory chronic cough: recent advances}

"Refractory" or unexplained chronic cough is defined by a chronic cough persisting despite assessment and treatment according to current guidelines. ${ }^{26}$ It represents $2.7 \%-46 \%$ of chronic cough. ${ }^{1,62}$

\section{New concepts}

The concept of chronic hypersensitivity syndrome (CHS) has been developed ${ }^{79}$ and considered clinically relevant by the ERS task force ${ }^{80} \mathrm{CHS}$ is associated with hypersensitivity of the larynx and upper airways. It is described as a disorder of sensory airway nerves caused by hypersensitivity to innocuous irritants linked to an upregulation of mucosal cough receptors, including the receptor channel transient receptor potential vanilloid (TRPV) type 1, a cough receptor triggering afferent nerve activity in response to cough-provoking stimuli (heat, acid, arachidonic acid derivatives). ${ }^{26,81,82}$ A questionnaire (Hull Airway Reflux Questionnaire, HARQ) has been developed for CHS diagnosis and exhibited a high sensitivity (94\%) and specificity (95\%). ${ }^{54} \mathrm{CHS}$ can apply to most patients with chronic cough, different phenotypes being defined by the underlying condition. Three main different phenotypes have been described: i) predominant phenotype of rhinal symptoms (such as UACS); ii) Th2-cell dominant phenotype (cough variant asthma or NAEB) and iii) predominant phenotype characterized by acid reflux and heartburn (gastroesophageal reflux cough). ${ }^{61}$ Refractory chronic cough is considered to be a phenotype of the CHS. ${ }^{80}$

Laryngeal hypersensitivity is defined as increased sensitivity of the larynx to innocuous stimuli.$^{83}$ Related symptoms are laryngeal paresthesia with cough, dyspnea, dysphonia, or laryngeal spasm. A specific questionnaire (laryngeal hypersensitivity questionnaire) is a validated tool that provides reproducible results. ${ }^{73} \mathrm{CHS}$ may overlap with other laryngeal hypersensitivity syndromes. ${ }^{26}$

The mechanisms involved in cough reflex hypersensibility, an important feature of refractory chronic cough, have recently been reviewed. ${ }^{26}$ Briefly, it involves both peripheral sensitization (inflammatory-mediated sensitization of cough fiber afferent nerve with subsequent reduced threshold for cough in upper and lower airways) and central sensitization (increased excitability in central sensory pathways). The very recent concept of "neurophenotype" in respiratory diseases has been postulated by Belvisi. ${ }^{84}$ In this study, the authors analyzed the patterns of cough response to inhaled irritants in different respiratory pathologies including COPD, asthma and refractory chronic cough. The results suggested a disease specific change in airway nerve function. Moreover, cigarette smoke exposure was able to induce phenotypic changes in airway nerve function. ${ }^{84}$ These concepts need to be further analyzed in order to completely understand the underlying mechanisms involved.

\section{Clinical presentation and explorations}

Refractory chronic cough occurs more frequently in women, with an intermittent dry cough throughout the day triggered by usually non-tussive stimuli, including talking, or low dose of tussive stimuli, associated with laryngeal paresthesia and frequent dysphonia. ${ }^{26}$ The diagnosis of refractory chronic cough is an exclusion diagnosis and requires the investigation of other causes as recommended by current guidelines. ${ }^{2}$

Flexible nasendoscopy for laryngeal examination will allow the identification of laryngeal lesions or abnormal motor patterns, signs of laryngopharyngeal reflux or abnormal response to exercise challenge in case of suspicion of paradoxical vocal fold movement. A systematic examination of laryngeal structure and function may be indicated in patients with refractory chronic cough associated with laryngeal symptoms. ${ }^{26}$

\section{Treatment of refractory chronic cough}

The treatment of unexplained and refractory chronic cough has recently been reviewed, ${ }^{85}$ and 4 types of treatment were identified, including non-pharmacologic therapies consisting of speech pathology-therapy based intervention; ICSs targeting mainly eosinophilic airway inflammation; neuromodulatory therapies acting on neural pathways; and other therapies, including esomeprazole, macrolides and ipratropium.

\section{Non-pharmacological treatment: speech pathology therapy}

Speech pathology treatment for chronic cough aims to improve voluntary control over the cough by teaching patients to identify sensations that precipitate the cough, to substitute the cough with another response (breathing or swallowing exercise), and to modify behaviors that contribute to laryngeal irritation. ${ }^{26,86}$ It is usually performed by speech pathologists and includes a first step of pathophysiological assessment (cough characteristics, urge to cough evaluation, laryngeal assessment and voice symptoms), followed by a program using several tools including education, cough 
suppression strategies, vocal hygiene training and psychoeducational counseling. ${ }^{26,86,87}$

Several studies aimed to analyze the impact of speech pathology interventions on refractory chronic cough. ${ }^{87-90}$ These studies identified a decrease in cough score and an improvement of total symptom score and daily limitation score, ${ }^{87} \mathrm{a}$ decrease in cough reflex hypersensitivity ${ }^{89}$ and in laryngeal hypersensitivity. ${ }^{90}$ Ryan et al also noted an improvement in both patients with refractory chronic cough alone and associated with paradoxical vocal fold movement. ${ }^{88}$ Recent guidelines suggest a therapeutic trial of multimodality speech pathology therapy in patients with unexplained chronic cough (Grade $2 \mathrm{C}$ recommendation). ${ }^{85}$

\section{ICSs}

ICSs are effective on eosinophilic airway inflammation. An assessment of airway eosinophilia (induced sputum, bronchoalveolar lavage) or exhaled NO should be part of the assessment of refractory chronic cough. ${ }^{26}$ An improvement of cough severity has been shown after ICS treatment. ${ }^{91}$ However, the population in this study probably included asthmatic subjects. ${ }^{85}$ No improvement of cough symptoms has been shown after budesonide treatment in patients with no asthma and no eosinophilia. ${ }^{92}$ The recent guidelines recommend ICS should not to be prescribed in adult patients with unexplained chronic cough and negative tests for bronchial hyperresponsiveness and eosinophilia (sputum eosinophils, exhaled nitric oxide) (Grade $2 \mathrm{~B}$ recommendation). ${ }^{85}$

\section{Neuromodulatory treatments}

Centrally acting neuromodulators act on the increased neural sensitization involved in the pathophysiology of refractory chronic cough. ${ }^{26}$ A positive effect on cough-specific QoL has been shown with amitriptyline, ${ }^{93}$ gabapentin ${ }^{94}$ and morphine. ${ }^{95}$ However, the occurrence of side-effects could limit their use. A pilot study performed on 16 subjects with refractory chronic cough showed an improvement of cough severity after treatment by tramadol. ${ }^{96}$ This result has to be confirmed by other studies. Two reviews ${ }^{97,98}$ identified a positive effect of neuromodulatory therapy (amitriptylin, gabapentin, pregabalin and baclofen) on cough severity and cough-specific QoL. Both reviews highlighted the need for well-designed additional studies. Recent guidelines indicate that in adult patients with unexplained chronic cough, it is suggested to perform a therapeutic trial of gabapentin as long as the potential side effects and the risk-benefit profile are discussed with patients before use of the medication, and there is a reassessment of the risk-benefit profile at 6 months before continuing the drug (Grade $2 \mathrm{C}$ recommendation). ${ }^{85}$

The association of pregabalin and speech pathology therapy has recently been shown to reduce cough symptoms and improve QoL compared to speech therapy alone in a randomized placebo control trial performed in 40 subjects with refractory chronic cough. ${ }^{99}$

\section{Other treatments}

No improvement of chronic cough parameters has been found after treatment with esomeprazole, ${ }^{100}$ erythromycin ${ }^{101}$ or azithromycin. ${ }^{102}$ The reported efficacy of ipratriopium bromide on cough severity ${ }^{103}$ can be linked to an inhibitory effect of this therapeutic class on TRPV1 receptors. ${ }^{104}$

\section{Refractory chronic cough in comorbid respiratory diseases}

Refractory chronic cough in lung cancer

Guidelines for the management of cough in lung cancer and its symptomatic treatment have been very recently published. ${ }^{23}$ In adults with cough associated with lung cancer that persists despite cancer treatment, the authors recommend a first assessment to identify coexisting causes. It is suggested to use a symptomatic management including cough suppression exercises and/or pharmacological therapy (demulcents, titrated opiate-derivative, peripherally acting antitussive or local anesthetics). ${ }^{23}$

\section{Refractory chronic cough in IPF}

A few studies assessed drugs specifically targeting cough in IPF. ${ }^{66}$ Talidomide treatment was associated with a decrease in cough and an increase in respiratory QoL. ${ }^{105}$ A positive effect of interferon- $\alpha$ was suggested in a small trial. ${ }^{106}$ The impact of steroids was equivocal, with potential important side effects. ${ }^{107,108}$ An encouraging recent study tested a novel formulation of nebulized sodium chromoglicate (PA101) in a randomized placebo controlled trial including 24 subjects with IPF and 28 participants with idiopathic chronic cough. Nebulizations were performed 3 times a day for 2 weeks. The authors described a $31.1 \%$ decrease of cough frequency in IPF-treated patients compared to placebo. No improvement was found in subjects with idiopathic chronic cough. ${ }^{109}$

\section{New drugs on trial}

\section{Sodium-channel inhibitor}

GSK2339345 is an inhibitor of voltage-gated sodium channels (VGSC) that are involved in afferent sensory nerve fibers responsible for evoking cough. This drug has been 
tested in a randomized, double-blind, placebo-controlled, cross-over study conducted in 16 patients in the UK. Despite reaching airway sensory nerves, this drug did not have any effect on cough. ${ }^{110}$

\section{TRPVI antagonists}

Two TRPV1 antagonists (XEN-D0501 and SB-705498) did not induce any improvement on cough frequency despite a clear pharmacological effect on cough reflex sensitivity to caspain. ${ }^{111,112}$

\section{$\mathrm{P} 2 \mathrm{X} 3$ antagonist}

$\mathrm{P} 2 \mathrm{X} 3$ receptors are thought to mediate sensitization of the cough reflex, leading to chronic cough. AF-219 is a P2X3 antagonist that has been tested in a double-blind, placebocontrolled, 2-period, crossover study in the UK in 24 subjects with chronic refractory cough. ${ }^{113}$ After 2 weeks of treatment, the authors observed a reduction of cough frequency by $75 \%$ in subjects treated with AF-219 compared to placebo. Taste disturbances were reported by all patients taking AF-219. $\mathrm{P} 2 \mathrm{X} 3$ receptors agonists could represent a new group of antitussive drugs.

\section{Conclusion}

Chronic cough management following current guidelines allows an efficient treatment in most cases. The new concepts of peripheral and central neural hypersensitivity and neurophenotypes allowed important advances in the comprehension of physiopathological mechanisms involved in refractory chronic cough. Based on these results, new drugs have been developed, whose clinical impact has to be further analyzed.

\section{Disclosure}

The authors report no conflicts of interest in this work.

\section{References}

1. Irwin RS, Baumann MH, Bolser DC, et al. Diagnosis and management of cough executive summary: ACCP evidence-based clinical practice guidelines. Chest. 2006;129(1 Suppl):1S-23S.

2. Irwin RS, French CL, Chang AB, Altman KW; CHEST Expert Cough Panel. Classification of cough as a symptom in adults and management algorithms: CHEST guideline and expert panel report. Chest. 2018; 153(1):196-209.

3. Chamberlain SA, Garrod R, Douiri A, et al. The impact of chronic cough: a cross-sectional European survey. Lung. 2015;193(3):401-408.

4. Birring SS, Kavanagh J, Lai K, Chang AB. Adult and paediatric cough guidelines: Ready for an overhaul? Pulm Pharmacol Ther. 2015;35: 137-144.

5. Song WJ, Chang YS, Faruqi S, et al. The global epidemiology of chronic cough in adults: a systematic review and meta-analysis. Eur Respir J. 2015;45(5):1479-1481.
6. Dicpinigaitis PV, Lim L, Farmakidis C. Cough syncope. Respir Med. 2014;108(2):244-251.

7. Stec SM, Grabczak EM, Bielicki P, et al. Diagnosis and management of premature ventricular complexes-associated chronic cough. Chest. 2009;135(6):1535-1541.

8. French CL, Crawford SL, Bova C, Irwin RS. Change in psychological, physiological, and situational factors in adults after treatment of chronic cough. Chest. 2017;152(3):547-562.

9. Hanak V, Hartman TE, Ryu JH. Cough-induced rib fractures. Mayo Clin Proc. 2005;80(7):879-882.

10. Boulet LP, Coeytaux RR, McCrory DC, et al. Tools for assessing outcomes in studies of chronic cough: CHEST guideline and expert panel report. Chest. 2015;147(3):804-814.

11. Pacheco A, de Diego A, Domingo C, et al. Chronic cough. Arch Bronconeumol. 2015;51(11):579-589.

12. Birring SS. Controversies in the evaluation and management of chronic cough. Am J Respir Crit Care Med. 2011;183(6):708-715.

13. Dalal B, Geraci SA. Office management of the patient with chronic cough. Am J Med. 2011;124(3):206-209.

14. Pavord ID, Chung KF. Management of chronic cough. Lancet. 2008; 371(9621):1375-1384.

15. Gibson PG, Chang AB, Glasgow NJ, et al. CICADA: Cough in children and adults: diagnosis and assessment. Australian cough guidelines summary statement. Med J Aust. 2010;192(5):265-271.

16. Morice AH, McGarvey L, Pavord I; British Thoracic Society Cough Guideline Group. Recommendations for the management of cough in adults. Thorax. 2006;61 Suppl 1:i1-i24.

17. Kardos P, Berck H, Fuchs KH, et al. Guidelines of the German Respiratory Society for diagnosis and treatment of adults suffering from acute or chronic cough. Pneumologie. 2010;64(11):701-711.

18. Kohno S, Ishida T, Uchida Y, et al. The Japanese Respiratory Society guidelines for management of cough. Respirology. 2006;11 Suppl 4: S135-S186.

19. Asthma Workgroup, Chinese Society Respiratory Diseases (CSRD), Chinese Medical Association. The Chinese national guidelines on diagnosis and management of cough (December 2010). Chin Med J (Engl). 2011;124(20):3207-3219.

20. Irwin RS, French CT, Lewis SZ, Diekemper RL, Gold PM; CHEST Expert Cough Panel. Overview of the management of cough: CHEST guideline and expert panel report. Chest. 2014;146(4):885-889.

21. Jiang M, Guan WJ, Fang ZF, et al. A critical review of the quality of cough clinical practice guidelines. Chest. 2016;150(4):777-788.

22. Wee B, Browning J, Adams A, et al. Management of chronic cough in patients receiving palliative care: review of evidence and recommendations by a task group of the Association for Palliative Medicine of Great Britain and Ireland. Palliat Med. 2012;26(6):780-787.

23. Molassiotis A, Smith JA, Mazzone P, Blackhall F, Irwin RS; CHEST Expert Cough Panel. Symptomatic treatment of cough among adult patients with lung cancer: CHEST guideline and expert panel report. Chest. 2017;151(4):861-874.

24. Moscato G, Pala G, Cullinan P, et al. EAACI position paper on assessment of cough in the workplace. Allergy. 2014;69(3):292-304.

25. French CT, Diekemper RL, Irwin RS, et al. Assessment of intervention fidelity and recommendations for researchers conducting studies on the diagnosis and treatment of chronic cough in the adult: CHEST guideline and expert panel report. Chest. 2015;148(1):32-54.

26. Gibson PG, Vertigan AE. Management of chronic refractory cough. BMJ. 2015;351:h5590.

27. Tarlo SM, Altman KW, French CT, Diekemper RL, Irwin RS. Evaluation of occupational and environmental factors in the assessment of chronic cough in adults: a systematic review. Chest. 2016;149(1):143-160.

28. Çolak Y, Nordestgaard BG, Laursen LC, Afzal S, Lange P, Dahl M. Risk factors for chronic cough among 14,669 individuals from the general population. Chest. 2017;152(3):563-573.

29. Anyenda EO, Higashi T, Kambayashi Y, et al. Associations of cough prevalence with ambient polycyclic aromatic hydrocarbons, nitrogen and sulphur dioxide: a longitudinal study. Int J Environ Res Public Health. 2016;13(8):pii:E800. 
30. Nieminen P, Panychev D, Lyalyushkin S, et al. Environmental exposure as an independent risk factor of chronic bronchitis in northwest Russia. Int J Circumpolar Health. 2013;72.

31. Hu ZW, Zhao YN, Cheng Y, et al. Living near a major road in Beijing: association with lower lung function, airway acidification, and chronic cough. Chin Med J (Engl). 2016;129(18):2184-2190.

32. Bentayeb M, Norback D, Bednarek M, et al. Indoor air quality, ventilation and respiratory health in elderly residents living in nursing homes in Europe. Eur Respir J. 2015;45(5):1228-1238.

33. Brugts JJ, Arima H, Remme W, et al. The incidence and clinical predictors of ACE-inhibitor induced dry cough by perindopril in 27,492 patients with vascular disease. Int J Cardiol. 2014;176(3): 718-723.

34. Dicpinigaitis PV. Angiotensin-converting enzyme inhibitor-induced cough: ACCP evidence-based clinical practice guidelines. Chest. 2006;129(1 Suppl):169S-173S.

35. Hallberg P, Nagy J, Karawajczyk M, et al. Comparison of clinical factors between patients with angiotensin-converting enzyme inhibitor-induced angioedema and cough. Ann Pharmacother. 2017;51(4):293-300.

36. Luo JQ, He FZ, Luo ZY, et al. Rs495828 polymorphism of the ABO gene is a predictor of enalapril-induced cough in Chinese patients with essential hypertension. Pharmacogenet Genomics. 2014;24(6): 306-313.

37. Mosley JD, Shaffer CM, Van Driest SL, et al. A genome-wide association study identifies variants in KCNIP4 associated with ACE inhibitorinduced cough. Pharmacogenomics J. 2016;16(3):231-237.

38. Undem BJ, Zaccone E, McGarvey L, Mazzone SB. Neural dysfunction following respiratory viral infection as a cause of chronic cough hypersensitivity. Pulm Pharmacol Ther. 2015;33:52-56.

39. Abdullah H, Heaney LG, Cosby SL, McGarvey LP. Rhinovirus upregulates transient receptor potential channels in a human neuronal cell line: implications for respiratory virus-induced cough reflex sensitivity. Thorax. 2014;69(1):46-54.

40. Braman SS. Chronic cough due to acute bronchitis: ACCP evidencebased clinical practice guidelines. Chest. 2006;129(1 Suppl): 95S-103S

41. Bock JM, Burtis CC, Poetker DM, Blumin JH, Frank MO. Serum immunoglobulin $\mathrm{G}$ analysis to establish a delayed diagnosis of chronic cough due to Bordetella pertussis. Otolaryngol Head Neck Surg. 2012 146(1):63-67.

42. Gilberg S, Njamkepo E, Du Châtelet IP, et al. Evidence of Bordetella pertussis infection in adults presenting with persistent cough in a French area with very high whole-cell vaccine coverage. J Infect Dis. 2002;186(3):415-418.

43. Moore A, Ashdown HF, Shinkins B, et al. Clinical characteristics of pertussis-associated cough in adults and children: a diagnostic systematic review and meta-analysis. Chest. 2017;152(2):353-367.

44. Dąbrowska M, Grabczak EM, Arcimowicz M, et al. Chronic cough assessment of treatment efficacy based on two questionnaires. Arch Med Sci. 2014;10(5):962-969.

45. Yu L, Qiu ZH, Wei WL, et al. Discrepancy between presumptive and definite causes of chronic cough. Chin Med J (Engl). 2011;124(24): 4138-4143.

46. Lai K, Chen R, Lin J, et al. A prospective, multicenter survey on causes of chronic cough in China. Chest. 2013;143(3):613-620.

47. Dicpinigaitis PV. Chronic cough due to asthma: ACCP evidence-based clinical practice guidelines. Chest. 2006;129(1 Suppl):75S-79S.

48. Lai K, Chen R, Peng W, Zhan W. Non-asthmatic eosinophilic bronchitis and its relationship with asthma. Pulm Pharmacol Ther. 2017; 47:66-71.

49. Song WJ, Kim HJ, Shim JS, et al. Diagnostic accuracy of fractional exhaled nitric oxide measurement in predicting cough-variant asthma and eosinophilic bronchitis in adults with chronic cough: a systematic review and meta-analysis. J Allergy Clin Immunol. 2017;140(3): 701-709.

50. Lai K, Liu B, Xu D, et al. Will nonasthmatic eosinophilic bronchitis develop into chronic airway obstruction? A prospective, observational study. Chest. 2015;148(4):887-894.
51. Fletcher KE, French CT, Irwin RS, Corapi KM, Norman GR. A prospective global measure, the Punum Ladder, provides more valid assessments of quality of life than a retrospective transition measure. J Clin Epidemiol. 2010;63(10):1123-1131.

52. Natt RS, Earis JE, Swift AC. Chronic cough: a multidisciplinary approach. J Laryngol Otol. 2012;126(5):441-444.

53. Wu DN, Yamauchi K, Kobayashi H, et al. Effects of esophageal acid perfusion on cough responsiveness in patients with bronchial asthma. Chest. 2002;122(2):505-509.

54. Morice AH. Chronic cough hypersensitivity syndrome. Cough. 2013;9(1):14.

55. Kahrilas PJ, Howden CW, Hughes N, Molloy-Bland M. Response of chronic cough to acid-suppressive therapy in patients with gastroesophageal reflux disease. Chest. 2013;143(3):605-612.

56. Gawron AJ, Kahrilas PJ, Pandolfino JE. Chronic cough: a gastroenterology perspective. Curr Opin Otolaryngol Head Neck Surg. 2013; 21(6):523-529.

57. Kahrilas PJ, Altman KW, Chang AB, et al. Chronic cough due to gastroesophageal reflux in adults: CHEST guideline and expert panel report. Chest. 2016;150(6):1341-1360.

58. Kitz R, Boehles HJ, Rosewich M, Rose MA. Lipid-laden alveolar macrophages and $\mathrm{pH}$ monitoring in gastroesophageal reflux-related respiratory symptoms. Pulm Med. 2012;2012:673637.

59. Decalmer S, Stovold R, Houghton LA, et al. Chronic cough: relationship between microaspiration, gastroesophageal reflux, and cough frequency. Chest. 2012;142(4):958-964.

60. Rosen R, Johnston N, Hart K, Khatwa U, Nurko S. The presence of pepsin in the lung and its relationship to pathologic gastro-esophageal reflux. Neurogastroenterol Motil. 2012;24(2):129-133, e84-e85.

61. Yu L, Xu X, Lv H, Qiu Z. Advances in upper airway cough syndrome. Kaohsiung J Med Sci. 2015;31(5):223-228.

62. Lee J, Kim M, Kim JH, Lee YR, Kim S, Kim Y. A cheaper, faster way to resolve chronic cough. J Fam Pract. 2007;56(8):641-646.

63. Levine BM. Systematic evaluation and treatment of chronic cough in a community setting. Allergy Asthma Proc. 2008;29(3):336-342.

64. Ribeiro M, De Castro Pereira CA, Nery LE, Beppu OS, Silva CO. A prospective longitudinal study of clinical characteristics, laboratory findings, diagnostic spectrum and outcomes of specific therapy in adult patients with chronic cough in a general respiratory clinic. Int J Clin Pract. 2006;60(7):799-805.

65. Deslee G, Burgel PR, Escamilla R, et al. Impact of current cough on health-related quality of life in patients with COPD. Int J Chron Obstruct Pulmon Dis. 2016;11:2091-2097.

66. Vigeland CL, Hughes AH, Horton MR. Etiology and treatment of cough in idiopathic pulmonary fibrosis. Respir Med. 2017;123: 98-104.

67. Sundar KM, Daly SE, Pearce MJ, Alward WT. Chronic cough and obstructive sleep apnea in a community-based pulmonary practice. Cough. 2010;6(1):2.

68. Sundar KM, Daly SE. Chronic cough and OSA: a new association? J Clin Sleep Med. 2011;7(6):669-677.

69. Chan KK, Ing AJ, Laks L, Cossa G, Rogers P, Birring SS. Chronic cough in patients with sleep-disordered breathing. Eur Respir J. 2010;35(2):368-372.

70. Wang TY, Lo YL, Liu WT, et al. Chronic cough and obstructive sleep apnoea in a sleep laboratory-based pulmonary practice. Cough. 2013; 9(1):24.

71. Chan K, Ing A, Birring SS. Cough in obstructive sleep apnoea. Pulm Pharmacol Ther. 2015;35:129-131.

72. Sundar KM, Daly SE, Willis AM. A longitudinal study of CPAP therapy for patients with chronic cough and obstructive sleep apnoea. Cough. 2013;9(1):19.

73. Vertigan AE, Murad MH, Pringsheim T, et al. Somatic cough syndrome (previously referred to as psychogenic cough) and tic cough (previously referred to as habit cough) in adults and children: CHEST guideline and expert panel report. Chest. 2015;148(1):24-31.

74. Vertigan AE. Somatic cough syndrome or psychogenic cough - what is the difference? J Thorac Dis. 2017;9(3):831-838. 
75. Song WJ, Morice AH, Kim MH, et al. Cough in the elderly population: relationships with multiple comorbidity. PLoS One. 2013;8(10): e78081.

76. Boulet LP, Turmel J, Irwin RS; CHEST Expert Cough Panel. Cough in the athlete: CHEST guideline and expert panel report. Chest. 2017; 151(2):441-454

77. Boulet LP. Cough and upper airway disorders in elite athletes: a critical review. Br J Sports Med. 2012;46(6):417-421.

78. Rosen MJ, Ireland B, Narasimhan M, French C, Irwin RS; CHEST Expert Cough Panel. Cough in ambulatory immunocompromised adults: CHEST expert panel report. Chest. 2017;152(5):1038-1042.

79. Morice AH, Faruqi S, Wright CE, Thompson R, Bland JM. Cough hypersensitivity syndrome: a distinct clinical entity. Lung. 2011;189(1): 73-79.

80. Morice AH, Millqvist E, Belvisi MG, et al. Expert opinion on the cough hypersensitivity syndrome in respiratory medicine. Eur Respir J. 2014;44(5):1132-1148.

81. Chung KF. Approach to chronic cough: the neuropathic basis for cough hypersensitivity syndrome. J Thorac Dis. 2014;6(Suppl 7):S699-S707.

82. Patberg KW. The female preponderance to cough hypersensitivity syndrome: another clue pointing to the role of TRPV1 in cough. Lung. 2011;189(3):257-258.

83. Ryan NM, Gibson PG. Characterization of laryngeal dysfunction in chronic persistent cough. Laryngoscope. 2009;119(4):640-645.

84. Belvisi MG, Birrell MA, Khalid S, et al. Neurophenotypes in airway diseases. insights from translational cough studies. Am J Respir Crit Care Med. 2016;193(12):1364-1372.

85. Gibson P, Wang G, McGarvey L, et al. Treatment of unexplained chronic cough: CHEST guideline and expert panel report. Chest. 2016; 149(1):27-44.

86. Chamberlain S, Garrod R, Birring SS. Cough suppression therapy: does it work? Pulm Pharmacol Ther. 2013;26(5):524-527.

87. Vertigan AE, Theodoros DG, Gibson PG, Winkworth AL. Efficacy of speech pathology management for chronic cough: a randomised placebo controlled trial of treatment efficacy. Thorax. 2006;61(12): 1065-1069.

88. Ryan NM, Vertigan AE, Gibson PG. Chronic cough and laryngeal dysfunction improve with specific treatment of cough and paradoxical vocal fold movement. Cough. 2009;5:4

89. Ryan NM, Vertigan AE, Bone S, Gibson PG. Cough reflex sensitivity improves with speech language pathology management of refractory chronic cough. Cough. 2010;6:5.

90. Murry T, Branski RC, Yu K, Cukier-Blaj S, Duflo S, Aviv JE. Laryngeal sensory deficits in patients with chronic cough and paradoxical vocal fold movement disorder. Laryngoscope. 2010;120(8):1576-1581.

91. Ribeiro M, Pereira CA, Nery LE, Beppu OS, Silva CO. High-dose inhaled beclomethasone treatment in patients with chronic cough: a randomized placebo-controlled study. Ann Allergy Asthma Immunol. 2007;99(1):61-68.

92. Pizzichini MM, Pizzichini E, Parameswaran K, et al. Nonasthmatic chronic cough: no effect of treatment with an inhaled corticosteroid in patients without sputum eosinophilia. Can Respir J. 1999;6(4): 323-330.

93. Jeyakumar A, Brickman TM, Haben M. Effectiveness of amitriptyline versus cough suppressants in the treatment of chronic cough resulting from postviral vagal neuropathy. Laryngoscope. 2006;116(12): 2108-2112.

94. Ryan NM, Birring SS, Gibson PG. Gabapentin for refractory chronic cough: a randomised, double-blind, placebo-controlled trial. Lancet. 2012;380(9853):1583-1589.

95. Morice AH, Menon MS, Mulrennan SA, et al. Opiate therapy in chronic cough. Am J Respir Crit Care Med. 2007;175(4):312-315.
96. Dion GR, Teng SE, Achlatis E, Fang Y, Amin MR. Treatment of neurogenic cough with tramadol: a pilot study. Otolaryngol Head Neck Surg. 2017;157(1):77-79.

97. Cohen SM, Misono S. Use of specific neuromodulators in the treatment of chronic, idiopathic cough: a systematic review. Otolaryngol Head Neck Surg. 2013;148(3):374-382.

98. Wei W, Liu R, ZhangTong Y, Qiu Z. The efficacy of specific neuromodulators on human refractory chronic cough: a systematic review and meta-analysis. J Thorac Dis. 2016;8(10):2942-2951.

99. Vertigan AE, Kapela SL, Ryan NM, Birring SS, McElduff P, Gibson PG. Pregabalin and speech pathology combination therapy for refractory chronic cough: a randomized controlled trial. Chest. 2016; 149(3):639-648.

100. Shaheen NJ, Crockett SD, Bright SD, et al. Randomised clinical trial: high-dose acid suppression for chronic cough - a double-blind, placebo-controlled study. Aliment Pharmacol Ther. 2011;33(2):225-234.

101. Yousaf N, Monteiro W, Parker D, Matos S, Birring S, Pavord ID. Longterm low-dose erythromycin in patients with unexplained chronic cough: a double-blind placebo controlled trial. Thorax. 2010;65(12): 1107-1110.

102. Hodgson D, Anderson J, Reynolds C, et al. The effects of azithromycin in treatment-resistant cough: a randomized, double-blind, placebocontrolled trial. Chest. 2016;149(4):1052-1060.

103. Holmes PW, Barter CE, Pierce RJ. Chronic persistent cough: use of ipratropium bromide in undiagnosed cases following upper respiratory tract infection. Respir Med. 1992;86(5):425-429.

104. Birrell MA, Bonvini SJ, Dubuis E, et al. Tiotropium modulates transient receptor potential V1 (TRPV1) in airway sensory nerves: a beneficial off-target effect? J Allergy Clin Immunol. 2014;133(3): 679-687.e9.

105. Horton MR, Santopietro V, Mathew L, et al. Thalidomide for the treatment of cough in idiopathic pulmonary fibrosis: a randomized trial. Ann Intern Med. 2012;157(6):398-406.

106. Lutherer LO, Nugent KM, Schoettle BW, et al. Low-dose oral interferon $\alpha$ possibly retards the progression of idiopathic pulmonary fibrosis and alleviates associated cough in some patients. Thorax. 2011; 66(5):446-447.

107. Key AL, Holt K, Hamilton A, Smith JA, Earis JE. Objective cough frequency in idiopathic pulmonary fibrosis. Cough. 2010;6:4.

108. Flaherty KR, Toews GB, Lynch JP, et al. Steroids in idiopathic pulmonary fibrosis: a prospective assessment of adverse reactions, response to therapy, and survival. Am J Med. 2001;110(4):278-282.

109. Birring SS, Wijsenbeek MS, Agrawal S, et al. A novel formulation of inhaled sodium cromoglicate (PA101) in idiopathic pulmonary fibrosis and chronic cough: a randomised, double-blind, proof-of-concept, phase 2 trial. Lancet Respir Med. 2017;5(10):806-815.

110. Smith JA, McGarvey LPA, Badri H, et al. Effects of a novel sodium channel blocker, GSK2339345, in patients with refractory chronic cough. Int J Clin Pharmacol Ther. 2017;55(9):712-719.

111. Belvisi MG, Birrell MA, Wortley MA, et al. XEN-D0501, a novel transient receptor potential vanilloid 1 antagonist, does not reduce cough in patients with refractory cough. Am J Respir Crit Care Med. 2017;196(10):1255-1263.

112. Khalid S, Murdoch R, Newlands A, et al. Transient receptor potential vanilloid 1 (TRPV1) antagonism in patients with refractory chronic cough: a double-blind randomized controlled trial. J Allergy Clin Immunol. 2014;134(1):56-62.

113. Abdulqawi R, Dockry $\mathrm{R}$, Holt $\mathrm{K}$, et al. $\mathrm{P} 2 \mathrm{X} 3$ receptor antagonist (AF-219) in refractory chronic cough: a randomised, double-blind, placebo-controlled phase 2 study. Lancet. 2015;385(9974):1198-1205. 
Therapeutics and Clinical Risk Management

Dovepress

\section{Publish your work in this journal}

Therapeutics and Clinical Risk Management is an international, peerreviewed journal of clinical therapeutics and risk management, focusing on concise rapid reporting of clinical studies in all therapeutic areas outcomes, safety, and programs for the effective, safe, and sustained use of medicines. This journal is indexed on PubMed Central, CAS,
EMBase, Scopus and the Elsevier Bibliographic databases. The manuscript management system is completely online and includes a very quick and fair peer-review system, which is all easy to use. Visit http://www.dovepress.com/testimonials.php to read real quotes from published authors.

Submit your manuscript here: http://www.dovepress.com/therapeutics-and-clinical-risk-management-journal 